\title{
EXPERIENCIA ESTÉTICA DESPUÉS DE ADORNO. REFLEXIONES EN TORNOA WELLMER, BERTRAM Y REBENTISCH*
}

\author{
Esteban Alejandro Juárez** \\ ejuarez@eci.unc.edu.ar \\ María Verónica Galfione*** \\ veronicagalfione@yahoo.com.ar
}

RESUMEN Este artículo dialoga con tres importantes reflexiones estéticas procedentes de la filosofía alemana contemporánea. En primer lugar, se ocupa del trabajo de Albrecht Wellmer, representante de la "segunda generación de la Teoría Crítica"; en segundo lugar, se refiere al abordaje del actual profesor de estética en Berlín, Georg W. Bertram; y, en última instancia, indaga los aportes de Juliane Rebentisch, coeditora de la nueva versión de la Zeitschrift für Sozialforschung. Si bien los planteos de estos autores presentan matices diversos, todos ellos son, de uno u otro modo, herederos de un incisivo proceso de reconsideración crítica de la teoría estética de Theodor $W$. Adorno que viene desarrollándose desde los años setenta. La intención del artículo es reconstruir la modalidad de crítica planteada por estos tres autores y explorar a partir de ello algunas líneas de desarrollo para un estética postadorniana.

Palabras Clave Estética, Teoría Crítica, Obra de arte.

* Artigo recebido em 30/09/2014 e aprovado em 15/12/2014.

** Escuela de Ciencias de la Información. Universidad Nacional de Córdoba.

*** Instituto de Humanidades. CONICET. Universidad Nacional de Córdoba. 
ABSTRACT This work dialogues with three important reflections on aesthetics, originating in contemporary German philosophy. First, the work of Albrecht Wellmer, representative of the "second generation of the Critical Theory," is analyzed. Second, the approach of the current professor of Aesthetics in Berlin, Georg W. Bertram, and ultimately the contributions of Juliane Rebentisch, co-editor of the new version of the "Zeitschrift für Sozialforschung". While the proposals of these authors have different nuances, they are all, in one way or another, heirs of a long process of critical review of the aesthetic theory of Theodor $W$. Adorno in development since the seventies.

Keywords Aesthetics, Critical Theory, Artwork.

\section{Introducción}

Este artículo se centra en tres importantes reflexiones, procedentes de la filosofía alemana contemporánea, sobre aquello que atañe actualmente a la estética y a la filosofía del arte. En primer lugar, trataremos el trabajo de Albrecht Wellmer, uno de los representantes de la llamada "segunda generación de la Teoría Crítica". En segundo lugar, abordaremos algunas ideas de Georg W. Bertram, actual profesor de la Freie Universität de Berlín. $\mathrm{Y}$, en última instancia, expondremos los aportes de Juliane Rebentisch, coeditora de la nueva versión de la "Revista de Investigación Social" y autora de "Estética de la instalación". Si bien los planteos de estos autores presentan matices diversos, el hilo conductor que justifica su tratamiento conjunto radica en que todos ellos son, de uno u otro modo, herederos de un largo proceso de reconsideración crítica de la teoría estética de Theodor W. Adorno que viene desarrollándose en Alemania desde los años setenta.

Por estimar que estas reflexiones se inscriben en el proceso de reconsideración del legado de Adorno, antes de referirnos puntualmente a las investigaciones de Wellmer, Bertram y Rebentisch, presentaremos algunas líneas generales de los debates vinculados con aquel proceso. Luego retomaremos las tres perspectivas enunciadas y esbozaremos algunas consideraciones relativas a las mismas. Nuestro propósito con todo ello consiste no solo en resaltar las contribuciones de Wellmer, Bertram y Rebenstich para la reflexión estética actual, sino también en bosquejar algunas ideas provisorias sobre las restricciones que estos aportes podrían imponer a las potencialidades políticas contenidas en la estética adorniana. 


\section{La teoría estética de Adorno en disputa}

Desde comienzos de los años setenta se viene realizando en Alemania un incisivo trabajo de reformulación de las categorías de la estética idealista tomando como pilar y blanco la estética adorniana. Un precedente temprano de este trabajo tiene su vórtice en las reacciones críticas de filósofos y teóricos de la literatura. A pesar de las diferentes procedencias de los cuestionamientos, el denominador común de los mismos consiste en la invectiva contra la férrea exigencia histórico-filosófica que Adorno establecía para la reflexión crítica de las obras de arte. ¿Acaso -se preguntaban algunos críticos durante la década de 1970- sería necesario sostener una dudosa filosofía de la historia orientada en términos de reconciliación para comprender aquello que refiere a la especificidad del arte?; en lo que respecta al trato con las obras de arte significativas, ¿le correspondería a la estética filosófica la tarea de dar cuenta del sentido de su situación histórica, de sus rupturas y sus tendencias? En definitiva, ¿el contenido concreto de estas obras tendría una estrecha relación con la idea de verdad que persigue la filosofía, tal como Adorno pensaba?

En este contexto, Rüdiger Bubner se destaca como uno de los críticos más perspicaces de los "excesos" de la estética adorniana. Bubner encuentra en la estética negativa de Adorno la misma dificultad que arrastra también la interpretación hermenéutica de la experiencia estética, esto es, una marcada tendencia a transformar al arte en un resorte adecuado para la resolución de problemas no-estéticos, es decir, filosóficos. Bubner remite a la estética hegeliana esta propensión a subordinar el ámbito estético a una verdad de orden filosófico y reafirma la necesidad de recurrir a la filosofía de Immanuel Kant a los fines de superar el carácter heterónomo de aquellas perspectivas. Tomando distancia frente a la ontologización de la obra de arte que tenía lugar en la tradición idealista, pero también de toda posible reducción de la esfera estética al momento subjetivo, Bubner transforma a la apariencia estética, en tanto correlato ontológico del juicio reflexionante, en el eje de sus reflexiones filosóficas. ${ }^{1}$ De esta forma, Bubner confía en haber reestablecido las condiciones de una estética que se mantuviese fiel a la idea de autonomía y que evitase los desbordes indeseados de la teoría estética de Adorno.

Frente a posturas como esta, Albrecht Wellmer rescata la "equívoca" referencia adorniana a las categorías de verdad, apariencia y reconciliación

1 "[...] si se quiere atribuir un nombre propio a esta actuación libre que no se halla sujeta a un objeto pero tampoco vinculada a un sujeto, entonces se nos ofrece el término apariencia. Pues la apariencia es justamente aquel momento dependiente que ha devenido autónomo y que constituye el rendimiento específico del juicio reflexionante" (Bubner, 1982, p. 39). 
para pensar el propio presente histórico: "Hay algo en el arte que nos conduce a interpretar al arte mismo - $\mathrm{o}$ al menos, a muchas obras de arte- como portador de verdad." 2 No obstante, Wellmer discute las premisas de la filosofía de la consciencia y de la filosofía de la historia que se imbrican en Adorno y que enturbian las potencialidades contenidas en aquellas categorías. En principio rechaza la posibilidad de explicar las pretensiones de verdad que eleva toda obra de arte a partir un concepto apofántico de verdad artística y sugiere la necesidad de aclarar la relación existente entre las pretensiones de validez estética de la obra [Stimmigkeit] y sus pretensiones de verdad por medio de la estructura del discurso estético. A esta posibilidad, que había estado vedada para Adorno en virtud del compromiso de su pensamiento con la filosofía de la consciencia, Wellmer accede por intermedio de la diferenciación del concepto de verdad que había trazado Jürgen Habermas desde una teoría de la acción comunicativa basada en una perspectiva pragmático-trascendental. Dicho en pocas palabras, la crítica de Habermas a la absolutización adorniana de la razón identificante habilita a Wellmer para desplazarse desde una estética centrada en la obra de arte a otra focalizada en el espectador. Pues, una vez reconocidas las potencialidades de liberación contenidas en el habla, Wellmer no necesita garantizar el potencial crítico de la esfera estética por medio de la apelación a una distancia radical, como aquella que introducía el concepto adorniano de obra de arte negativa. Y esto sería así porque dicho potencial ahora puede ser remitido a la propia apertura de mundo [Welterschließung] que se produce durante el proceso discursivo de la recepción.

Asimismo, Wellmer reconoce un momento de verdad en la crítica bubneriana a las estéticas de la verdad por su tendencia a subordinar la experiencia estética a criterios de orden filosófico. Por ello, ya en "Verdad, apariencia, reconciliación" toma cierta distancia de la perspectiva habermasiana y busca determinar la especificidad de la recepción estética con respecto a la razón comunicativa. En este sentido, Wellmer sostiene que la obra de arte no puede ser interpretada mediante la analogía con algún tipo específico de acto de habla. De este modo, si bien Wellmer se mantiene en su voluntad de incorporar la actividad atributiva del receptor $-\mathrm{y}$ de abandonar una perspectiva a partir de la cual se suponía que la verdad del arte se hallaba encerrada en la obra y que debía ser extraído de ella por medio de la reflexión-, no confunde por ello esta verdad con la acción lingüística orientada al entendimiento. Por el contrario, tomando como eje el proceso de recepción de la obra de arte, 
Wellmer define a la verdad estética como un "fenómeno de interferencia" entre los tres conceptos habermasianos de verdad: el cognitivo, el práctico-moral y el expresivo. ${ }^{3}$ Podría decirse entonces que la dimensión estética se encuentra en contacto con las demás esferas, aunque sin identificarse con ninguna de ellas, y que su verdad -y, con ella, su potencial crítico de transformación-, remite a la ampliación de los horizontes comprensivos que la obra de arte hace posible en los receptores en función su propia "multilateralidad". 4

De manera que, en el proceso de recepción, el arte haría valer el potencial emancipador de la modernidad con respecto a los resabios de los poderes mistificadores en la medida en que permitiría pensar un nuevo tipo de síntesis o de "unidad no coactiva de lo múltiple",, en la cual lo no integrado podría encontrar su lugar en un espacio intersubjetivo donde prime una comunicación libre de dominio: "Esto sería", sostiene Wellmer, "una modernidad que no reconociera en la caída de la metafísica una pérdida sino una liberación: una liberación de la ilusión y del temor de un sentido último y abarcador de carácter objetivable; una modernidad que necesitaría cada vez menos la metafísica en la medida en que hubiese superado la necesidad de la misma en las estructuras seculares". 6

A comienzos de la década de 1990, Martin Seel y Christoph Menke exponen planteos alternativos a la posibilidad de concebir la validez de la esfera estética en los términos wellmerianos de un fenómeno de interferencia. Desde la perspectiva de Seel, la explicación de Wellmer se manifestaba insuficiente porque, por una parte, no permitía determinar la diferencia de la apertura de mundo que hace posible el arte con respecto a aquellas que tienen lugar en el ámbito no estético y, por otra, porque se limitaba a atribuirle al aparecer estético una validez de carácter derivado o sencillamente parasitario. ${ }^{7} \mathrm{En} \mathrm{su}$ "Estética del aparecer", ${ }^{8}$ Seel considera que solo resulta posible determinar los elementos distintivos de la experiencia estética si se supera la contraposición entre aquellos que interpretan la apariencia estética como (de)velación de aspectos del mundo empírico y aquellos que la entienden como trascendencia de ese mundo. Para Seel, esto se logra si se replantean las formas de la

3 Ibidem, pp. 30-31.

4 Idem, p. 35. Cf. Borgdorff, 1998, pp. 80-102.

5 Al respecto, véase Wellmer, 1994, especialmente pp. 31s.

6 Wellmer, 1993, p. 203.

7 Desde el punto de vista de Seel, la apariencia estética no es "el manifestarse de algo" sino "el manifestarse de sí misma”. Cf. Seel, 1996, pp. 105, 109. No se puede pasar por alto aquí la tentativa más radical de Karl Heinz Bohrer, quien intenta purificar a la apariencia estética de todo sentido extraestético, de toda pretensión de verdad, de todo contenido reconciliatorio o histórico-filosófico. La apariencia sería, para él, la epifanía del instante, del presente. Cf. Bohrer, 1981, pp. 111-138.

8 Seel, 2010. 
apariencia estética aquí implicadas y se las formula como modulaciones del "aparecer" [Erscheinen] estético.

Una reelaboración diferente de estos problemas puede encontrarse en el trabajo de Menke, quien procura repensar en términos semióticos las aporías constitutivas de la concepción adorniana de la obra de arte. Para Menke no se trataría de renunciar a la doble determinación de la obra en tanto poder trascendente y particularización con leyes propias -o, en palabras de Wellmer, a la tensión entre una verdad de carácter apofántico y otra de naturaleza estética- sino de remitir dichos momentos a la experiencia estética $\mathrm{o}$, más precisamente, a los procesos interpretativos que tienen lugar en el marco de la misma. Según lo expresa Menke en "La soberanía del arte", la eliminación de algunos de los elementos mencionados supondría el abandono de la especificidad de la dimensión estética o la renuncia al potencial trasgresor del ámbito estético sobre los discursos normativos de carácter extraestético. Esta última sería la postura asumida por las concepciones puristas del arte por el arte, mientras que la primera alternativa haría referencia tanto a las corrientes vanguardistas como a aquellas concepciones hermenéuticas del proceso de recepción estética. La concepción del arte por el arte nos enfrentaría al peligro del positivismo, en la medida en que la renuncia a la referencia del arte a una verdad en sentido enfático clausuraría toda posible generalización de las determinaciones estéticas. La otra perspectiva nos conduciría, en cambio, a la disolución de los límites artísticos y a la sujeción del ámbito estético a criterios de naturaleza extraestética.

Desde la perspectiva de Menke, solo una concepción estética de corte negativo podría hallarse en condiciones de resolver este dilema en la medida en que la misma permitiría comprender la doble determinación del arte moderno, esto es, su carácter autónomo, en tanto discurso específico entre otros discursos, y su potencial soberano, es decir, su capacidad para subvertir la razón de todos los demás ámbitos discursivos. "Entendida como negatividad", asevera Menke, "la experiencia estética adquiere un contenido soberano que, lejos de amputar la autonomía de la esfera artística, la presupone".

Pero Adorno había concebido la articulación del principio de la autonomía (validez estética o Stimmigkeit) con el principio de la soberanía (verdad apofántica) como un movimiento interno a la obra de arte. En función de su propia concordancia estética [Stimmigkeit], la obra de arte se presentaba como promesa de reconciliación. No obstante, en la medida 
en que solo como apariencia estética el arte podía proyectarse más allá del ámbito estético, aquel debía volverse contra su propio momento de falsedad, es decir, quebrar la promesa que hacía posible, y presentarse bajo la forma de arte negativo radical. "El arte", señala Menke en este sentido, "sólo puede afirmar que es más que mera apariencia, ya que es precisamente nada más que apariencia". ${ }^{10}$ Sin embargo, en opinión de Menke, este planteo del problema se hallaba expuesto al riesgo de reducir el ámbito estético a la determinación heterónoma de la filosofía. Ya que "es la filosofía misma el medio que produce el descubrimiento generalizador de la negatividad estética aun en nuestros discursos no estéticos". ${ }^{11}$

Ciertamente, Menke está convencido de que la concepción estética de Adorno no traería aparejada la instrumentación filosófica del arte en tanto recurso adecuado para la resolución de problemas de naturaleza no específicamente estética. Para Adorno, advierte Menke, "el arte no resuelve aporías diagnosticadas con anterioridad a la experiencia estética, sino que confronta las prácticas y discursos no estéticos con una experiencia crítica ante la cual estos se convierten en aporéticos o inextricablemente dialécticos". ${ }^{12} \mathrm{El}$ problema que descubre Menke en la perspectiva adorniana radica, más bien, en el hecho de que sea la filosofía la encargada de proyectar la negatividad estética sobre los discursos extraestéticos. Desde su punto de vista, en cambio, la filosofía debería limitarse a reconstruir las condiciones de posibilidad de aquellas generalizaciones de la estética que, más allá de su intervención, tienen lugar en el ámbito de la crítica y de la recepción estética.

\section{Wellmer y la destrucción de la estética idealista}

Retomando a Wellmer, se podría decir que su posicionamiento frente a la estética adorniana ha atravesado diversas fases. En términos generales, deberíamos afirmar que tras el intento de reformularla a partir de la teoría de la acción comunicativa de Habermas, Wellmer comienza a matizar el alcance de esta última para pensar un sujeto excéntrico, "no idéntico", sin abandonar del todo el potencial racional inacabable del entendimiento mutuo. ${ }^{13}$ Esta nueva modulación de su pensamiento se debe en gran parte a la incorporación de algunos elementos provenientes del deconstructivismo francés, el cual le 
permite reelaborar el problema de la relación entre el concepto de verdad y la dimensión estética. En sintonía con esta perspectiva, Wellmer se ha esforzado por interpretar la estética negativa de Adorno en términos de una deconstrucción de la estética idealista, esto es, en términos que ya no deberían remitir a los supuestos metafísicos ni de una filosofía de la reconciliación, ni de una dialéctica sujeto-objeto, ni tampoco de una filosofía de la historia.

En el artículo "La promesa de felicidad y por qué esta debe ser quebrada", ${ }^{14}$ Wellmer distingue dos posibles lecturas de la estética adorniana: una lectura ortodoxa, que Wellmer encuentra todavía asociada a la filosofía de la reconciliación, y otra, la suya, que denomina estereoscópica y que redefine el concepto de verdad de una manera inmanente a la propia apariencia estética. La lectura estereoscópica de la estética negativa de Adorno permite diferenciar un quiebre de la apariencia estética de carácter intraestético de otro que se presentaría como la consecuencia de una crítica social. A esta última interpretación del lema adorniano de la promesa de felicidad quebrada, según la cual esta última resultaría dependiente de un proyecto históricofilosófico, Wellmer le opone una fenomenología de la experiencia estética que posibilitaría inscribir el concepto de verdad en el propio juego estético, es decir, sin remisiones a un "aparecer" de la verdad extraestética. Según sostiene Wellmer, dicho análisis se hallaría presente en algunos pasajes de "Teoría estética" y se caracterizaría por definir la experiencia estética de una manera procesual, esto es, como un inacabable oscilar entre los polos de una comprensión mimética y de un esfuerzo hermenéutico-reflexivo. De este modo, la verdad estética estaría ceñida a la propia experiencia estética, la cual sería entendida por Wellmer como el proceso de deconstrucción de "la apariencia de la apariencia estética". O para decirlo más precisamente: como aquella experiencia que pone en crisis la identificación de la apariencia estética con un significado que excede la dimensión propiamente estética.

El cambio de perspectiva de Wellmer se refleja paradigmáticamente en su análisis de la presentación del encuentro de Odiseo con las sirenas que realizan Adorno y Horkheimer en el "Excurso" sobre el relato homérico de "Dialéctica de la Ilustración". En su escrito "La muerte de las sirenas y el origen de la obra de arte", ${ }^{15}$ Wellmer expone tres interpretaciones de este episodio. Estas interpretaciones remiten el episodio de las sirenas, por un lado, al proceso de neutralización y despotenciación del arte dentro de la sociedad burguesa y, por otro, a la dominación de la mujer en el marco de las sociedades 
patriarcales. Wellmer intenta mostrar hasta qué punto la primera lectura del episodio solo resulta verosímil en la medida en que se entrecruzan en ella elementos provenientes de la segunda interpretación. Desde la perspectiva del autor, esto equivale a demostrar la inconsistencia de la equiparación del canto de las sirenas con el "arte auténtico" que surgieren los autores del "Excurso".

El tercer abordaje del relato homérico, que será defendido por Wellmer, pone el énfasis tanto en el proceso de configuración de un yo reflexivo como en la emergencia de la belleza y del placer estético. Dicho en pocas palabras, la figura de Odiseo atado al mástil haría referencia al surgimiento de la apariencia estética y no ya a la domesticación de la fuerza subversiva del fenómeno artístico. Esta tercera interpretación del "Excurso" toma como punto de partida el cuestionamiento habermasiano a la absolutización de la crítica a la razón instrumental que tendría lugar en el marco de "Dialéctica de la Ilustración". La lectura de Wellmer procura poner en evidencia el carácter inadecuado de la reconstrucción del origen del sí mismo y del pensamiento conceptual, que es presentada en dicha obra, y de la consecuente disociación del horizonte utópico con respecto a la historia real. Por medio de una meticulosa disección de la obra de Adorno, Wellmer hace depender la constitución de un yo reflexivo de la inclusión de un momento de no-identidad, y equipara dicha noidentidad con aquel elemento que sería puesto en peligro por el canto seductor de las sirenas. Como puede advertirse, para Wellmer el canto de las sirenas no debería ser interpretado como la promesa de un futuro de felicidad plena que se encontraría hacia el final de la historia y que sería truncado en el marco de la sociedad burguesa, sino que simbolizaría más bien el deseo regresivo de un estado indiferenciado, de una felicidad completa, total e indivisa. Desde el punto de vista del autor, el surgimiento de la apariencia estética supondría, en este sentido, el fin de la influencia de la magia y la apertura de un espacio de libertad para el ejercicio lingüístico; esto es, lo que aquí estaría en juego sería la superación de la dialéctica sujeto-objeto, de la que partirían Adorno y Horkheimer, y la instauración de una nueva dimensión en el marco de la cual sería posible un trato intersubjetivo de carácter no objetivador, no violento. Wellmer cree encontrar elementos de apoyo para esta última lectura, no obstante, en el propio "Excurso" de "Dialéctica de la Ilustración", en la medida en que este alude a la distancia que media entre la epopeya homérica y el mundo propiamente mítico. En tanto apariencia estética, el relato homérico haría posible el distanciamiento con respecto al mal acaecido y jugaría, así, un rol determinante en la constitución de un sí mismo diferenciado, rebelde, reflexivo y, sobre todo, no-idéntico. 


\section{La hermenéutica de la apariencia estética según Georg Bertram}

En "El potencial utópico del arte después de Adorno. Una reactualización”, ${ }^{16}$ Georg W. Bertram, antiguo discípulo de Wellmer, vuelve a tocar un tema central en los debates en torno a la actualidad de la estética materialista de Adorno. Tomando como eje la concepción adorniana del potencial utópico del arte, Bertram intenta dar una respuesta productiva que disipe la tensión irresuelta, subyacente en la estética negativa, entre arte radical y procesos de transformación del mundo. Pues, para Adorno, en medio de la falta de libertad reinante en la realidad social y del predominio de la racionalidad identificadora, el arte no era un medio para cambiar al mundo, sino el lugar en que se configuraba la utopía. La fuerza para revolucionar materialmente la existencia y cumplir la promesa de felicidad encerrada en el arte debía proceder de otras dimensiones de la praxis humana. Sin embargo, a juicio de Bertram, a pesar de que Adorno había limitado en estos términos las fuerzas del arte, sus reflexiones sobre el potencial utópico de la experiencia artística pueden volverse fructíferas para pensar los procesos de transformación en la vida cotidiana. Para ello, como muestra el autor, es necesario prescindir de la premisa del negativismo social que sustentaba el planteo de Adorno, para concentrarse, en cambio, en el modo en que el frankfurtiano asentaba el potencial utópico de las obras de arte en el trato específico con las mismas.

Cada obra de arte es -en esto Bertram parafrasea a Adorno- un campo de tensiones, es decir, una articulación concreta de distintos elementos y procedimientos. La configuración estética que resulta de la articulación artística implica un proceso experiencial. La idea de Bertram se vincula aquí a la concepción adorniana del carácter procesual de la obra de arte como así también a la noción del arte como experiencia viva. ${ }^{17}$ Sin embargo, en Bertram esta idea ya no está sujeta a las premisas de la estética de Adorno del primado a la obra, ni tampoco a la negatividad que moldeaba su noción de experiencia. En efecto, a diferencia de Adorno, Bertram enfatiza que la experiencia artística no tiene un carácter meramente negativo. Para el autor, en concordancia con el proyecto crítico de Wellmer, el rol de la experiencia estética consiste principalmente en afirmar, potenciar y desestabilizar la comprensión que los hombres tienen de ellos mismos y del mundo.

Para sostener esta idea, Bertram define al arte como una forma de praxis que conlleva una toma de consciencia. ${ }^{18}$ Los procesos artísticos de toma de 
conciencia se diferencian de otras formas de praxis por el hecho de que dependen de la resistencia que ejercen los aspectos materiales y sensibles sobre la comprensión de la obra de arte. En este sentido, los materiales estéticos deben ser comprendidos en tanto materiales, y no como meros vehículos de comunicación de un significado. Dicho en otros términos, ellos representan un elemento irremplazable de la producción de significado, puesto que desencadenan un movimiento autorreflexivo que tematiza la propia constitución del arte como objeto.

Sin embargo, la resistencia que oponen los materiales estéticos a su asimilación comprensiva por parte del receptor no tiene como consecuencia la negación del aspecto comunicativo de la experiencia estética. Por ello mismo, el autor advierte acerca de la necesidad de complementar los análisis de Adorno sobre la utopía y el comportamiento mimético por medio de una noción de comprensibilidad amplia, de una elucidación del nexo entre experiencia estética e interpretación de las obras y de una revalorización del carácter afirmativo de la praxis racional.

El resultado de todo ello es una perspectiva que en poco se asemeja al planteo original de Adorno. Pues, para Bertram, la dimensión utópica del arte no estaría enlazada ni con el cuestionamiento radical de una racionalidad totalmente instrumentalizada ni con la resistencia del arte a la comprensibilidad y comunicabilidad, ${ }^{19}$ como pensaba Adorno. La racionalidad del arte desplazaría el principio de racionalidad, no lo diluiría. Y la comprensión, más que impedirse, podría mejorarse si se aclarara el lazo, insatisfactoriamente explicado por el teórico de Frankfurt, entre interpretación y experiencia estética. Este es justamente el objetivo que guía las reflexiones de Bertram en torno a la confrontación comprensiva con las obras de arte, ya que dichas reflexiones procuran clarificar y completar el concepto adorniano de comportamiento mimético.

Así, al igual que Adorno, Bertram considera que el significado de las obras de arte no puede asegurase de manera identificadora, como sucede en otras esferas de la vida social. No obstante, para Bertram esto no quiere decir que las obras se hallen completamente cerradas a la comprensión. Desde su punto de vista, ellas poseen también una dimensión comunicativa. Pues, de lo

19 Con respecto a este punto Bertram sostiene: "Las configuraciones específicas de elementos que cada obra de arte produce obstruyen la conexión con algo establecido. Sin embargo, de allí no se sigue que el significado de las obras de arte se halle velado. Solo se trata de que este no se puede asegurar de manera identificadora, como sucede en el caso de otras representaciones. Sin embargo, por medio de las formas de comportamiento mimético, que son exigidas por la obra de arte, se puede explorar perfectamente su significado" (Bertram, 2009, pp. 258s.). 
contrario, el mensaje utópico que contienen no podría ser captado de ninguna manera por los receptores. En este punto se acentúa la distancia que separa a Bertram de Adorno y se acrecienta el lazo con Wellmer. Puesto que si este consideraba que el carácter no identificador de la experiencia estética obstruía toda posible comprensión, aquel insiste en la posibilidad de que las formas de comportamiento mimético, que son exigidas por la obra de arte, se estabilicen en determinados modelos de articulación que vuelvan comprensible algunos momentos de la configuración de las obras. Según Bertram, estos modelos plantean exigencias transformadoras -soberanas en términos de Menke-a las demás prácticas humanas puesto que tienen su origen en una actitud receptiva por parte del espectador o, dicho en otros términos, porque la configuración específica de elementos de cada obra rompe con todo acceso que conecte con algo establecido. Justamente en este umbral se despliega el potencial utópico de las obras. En primer lugar, la confrontación comprensiva con las obras de arte ofrece modelos de articulación que pueden ser puestos en prácticas más allá del ámbito artístico. En segundo lugar, aquella remite más allá de las formas identificadoras de articulación que son practicadas en la vida cotidiana.

No obstante, llegados hasta aquí resulta evidente que el planteo de Bertram presupone una revisión del pensamiento de Adorno que trasciende el plano estético. Concretamente lo que Bertram cuestiona es la equiparación adorniana de la racionalidad con la razón identificatoria que subyace al diagnóstico de "Dialéctica de la Ilustración". Para Bertram, la racionalidad no solo remite al dominio de la naturaleza sino también al modo en que nos relacionamos con aquellas formas de dominio. Y es este el aspecto en el cual el arte deviene relevante. Él sería, según Bertram, una forma de autointerpretación (Ch. Taylor), de nosotros mismos y del mundo, que produce transformaciones; una "praxis de apropiación y desarrollo de la racionalidad" que no se rige por el principio de identificación.

De acuerdo con Bertram, este planteo no va en detrimento de la dimensión crítica de la racionalidad que Adorno le atribuía a la experiencia estética. En consonancia con Wellmer y con Menke, Bertram no desea perder la fuerza crítica del planteo adorniano y considera que cualquier forma de praxis racional normalizada es desafiada por ella, es decir, la experiencia artística desestabilizaría cualquier solidificación de las autointerpretaciones. El arte sería, en definitiva, una praxis mimética y al mismo tiempo racional, dentro de una situación histórica determinada. Y la experiencia artística podría así cuestionar las formas de praxis sociales entumecidas que se hallan enmarcadas en dicha situación. 


\section{EI problema de la estetización de la política y la politicidad del arte}

El debate postadorniano ha cobrado en Alemania un nuevo impulso gracias a los recientes estudios de Juliane Rebentisch. Su interés por repensar algunas categorías de la estética de Adorno resulta comprensible sobre el transfondo de sus reflexiones acerca de la situación política contemporánea. Dentro del espectro de inquietudes que entraña el vínculo actual entre estética y política, en Rebentisch sobresale su dedicación a los problemas surgidos del proceso de estetización de la esfera política. En un libro publicado en el año 2012, "El arte de la libertad. Para una dialéctica de la existencia democrática", ${ }^{20}$ la autora realiza una detallada revisión de los debates que han tenido lugar a lo largo de la historia de la filosofía en torno al concepto de una estetización de la política. Frente a aquellas perspectivas que toman como punto de partida el imperativo de una creación libre de uno mismo, ${ }^{21}$ Rebentisch retoma la referencia hegeliana a la dependencia de la libertad individual con respecto a la propia instancia de la praxis social. Sin embargo, su objetivo no consiste en reafirmar de este modo la condena hegeliana de la figura "estética" de la libertad en tanto mera libertad de carácter arbitrario. A diferencia de Hegel, que descubría en aquella figura una "libertad con respecto a lo social en general", Rebentisch interpreta la disposición estética como un distanciamiento parcial de las relaciones sociales objetivas. ${ }^{22} \mathrm{E}$ ámbito estético no promovería así una distancia relativa a toda determinación social -la mala realidad empírica- sino, más bien, un distanciamiento puntual en lo atinente a determinados aspectos concretos que configuran la identidad social de cada individuo en particular.

Sin embargo, la estrategia de la autora no solo consiste en mostrar que las conductas estetizantes no traerían aparejada la negación de la importancia del ámbito social para la autocomprensión del individuo singular. Contra la crítica conservadora del reinado de la apariencia estética, Rebentisch procura evidenciar, además, hasta qué punto el distanciamiento estético con respecto a las determinaciones colectivas establecidas puede ser comprendido como un momento constitutivo de la propia praxis social. A tales efectos, ella se vale de algunas teorías contemporáneas de la organización democrática ${ }^{23}$ que niegan el carácter natural de la unidad política y que enfatizan la relevancia de una autocorrección permanente de las instituciones y de las regulaciones

20 Rebentisch, 2012.

21 Rebenstich se refiere paradigmática a Wolfgang Welsch. Cf. Welsch, 1996.

22 Rebentisch, 2012, pp. 91-149.

23 Rebentisch remite de manera explícita a Claude Lefort y Jacques Rancière a la hora de pensar el problema de la democracia. Cf. Ranciére, 1996 y Lefort y Gauchet, 1971. 
socialmente reconocidas. Pues, partiendo de estas teorías, la toma de distancia reflexiva que introduce el comportamiento estético puede ser reinterpretada como un presupuesto necesario, tanto para la apropiación autoafirmativa como para la transformación de aquella praxis social que nos determina desde el comienzo. Dicho en otras palabras, el distanciamiento estético haría posible una diferencia relativa a los roles socialmente estipulados que resultaría indispensable a la hora de formular preguntas normativas de carácter individual y colectivo. En este sentido, concluye Rebentisch, el distanciamiento estético no constituiría un "modelo para la realización vital práctica del sujeto" sino más bien "un momento productivo en el marco de la misma". ${ }^{24}$

La defensa de la estética que realiza Rebentisch supone una significativa redefinición de algunos conceptos fundamentales de la tradición. Pues, si bien la autora se niega a caracterizar el comportamiento estético en términos de un ejercicio de la soberanía subjetiva frente a toda instancia de carácter objetivo, tampoco se halla dispuesta a asumir un concepto modernista de obra de arte. ${ }^{25}$ Lo primero significaría adherir a una postura posmoderna y reafirmar así la transformación de motivos estéticos tradicionales, tales como la creatividad, la espontaneidad, la originalidad, en una fuerza productiva del sistema capitalista. Sin embargo, los cambios que se produjeron en los últimos años en el terreno artístico tornan igualmente imposible la conservación del concepto modernista de obra de arte, gracias al cual autores como Adorno habían podido reivindicar el potencial político de la esfera artística. ${ }^{26}$ De hecho, una de las consecuencias de la incorporación de la perspectiva del espectador, que tuvo lugar desde comienzo de los años sesenta y cuya resonancia impregna los enfoques de Wellmer y Bertram, fue la puesta en cuestión de la centralidad de la obra de arte como piedra de toque del proceso interpretativo.

En este contexto, Rebentisch sostiene la necesidad de redefinir el concepto de obra de arte a los fines de diferenciar la experiencia estética de aquellas relaciones cosificadoras que tendrían lugar en las demás esferas de la realidad social, sin renunciar por ello a la posibilidad de dar cuenta de los hechos artísticos contemporáneos. ${ }^{27}$ En suma, la estrategia de Rebentisch

24 Rebentisch, 2012, p. 20.

25 Desde el punto de vista de Rebenstisch la defensa del concepto de obra de arte tradicional que realizan autores como Adorno tendría como consecuencia una imposibilidad de dar cuenta del arte contemporáneo. De hecho, desde la perspectiva de Adorno la progresiva dependencia de las obras contemporáneas con respecto a la perspectiva preformativa del espectador supondría la subordinación de la esfera artística a un comportamiento de carácter instrumental. Ya Peter Bürger había cuestionado la imposibilidad de Adorno de comprender las vanguardias históricas debido al apego de su estética a la teoría de la obra de arte; véase, Bürger, 1996, p. 98.

26 Cf. Adorno, 1982, p. 209.

27 Rebentisch, 2003. 
modula en clave política una tendencia que ya se encontraba en el núcleo de las posiciones estéticas de sus antecesores Wellmer, Menke y Bertram, pues aquella estrategia consiste, en última instancia, en remitir la especificidad de la obra de arte a la tendencia de la misma a exigir una atribución de sentido por parte del espectador y a frustrar permanentemente toda posible cristalización de tales significaciones. Las obras de arte harían posible así una experiencia que se caracterizaría por la tensión entre la percepción de un objeto de carácter material y la lectura simbólica del mismo y que por ello mismo se presentaría como portadora de un significado político. Puesto que el comportamiento reflexivo con respecto a representaciones subjetivas, que haría posible la experiencia estética, permitiría poner en cuestión aquella praxis colectiva en el marco de la cual dichas representaciones han sido establecidas y reconocidas como tales. "Por medio de ellas", resume la autora, "yo modifico la praxis de la cual formo parte." 28

\section{Consideraciones finales}

La interpretación de Wellmer sitúa la experiencia estética en relación con las categorías adornianas de apariencia, verdad y utopía. Sin embargo, lo hace en un marco de referencia que ya no remite a la obra de arte ni al discurso de la filosofía de la reconciliación que subyacía al planteo de Adorno. A partir de su reconstrucción de las secciones de "Teoría estética" en las cuales se inserta la trama argumentativa de la fórmula stendhaliana del arte como promesse du bonheur, Wellmer llega a la conclusión de que sería necesario abandonar los presupuestos idealistas adornianos vinculados a la filosofía de la historia y a la teología negativa de la reconciliación. Como veíamos, este autor considera que así sería posible desplazar el significado de la promesa que se halla conectada al carácter apariencial del arte y entenderlo de manera metafórica como la inacabable procesualidad de la experiencia estética en el marco de una teoría de la intersubjetividad. En este sentido, podría decirse que el foco del análisis wellmeriano queda fijado en el ámbito de la recepción estética, y vinculado a la posibilidad de una apropiación estética de estratos de experiencia ajenos al sentido y al sujeto. Desde este modo, se diluye la fuerte exigencia adorniana de que la obra de arte se relacione, desde su proceder inmanente, con la esfera política y la transformación cualitativa de lo social, es decir, se pierde la riqueza de la referencia a la dialéctica materialista de la 
felicidad contenida en el análisis de la promesse du bonheur que orientaba la idea del arte negativo en Adorno.

Algo similar sucede con su discípulo Bertram. Reivindicando el aspecto comunicativo y de la recepción del arte, Bertram intenta complementar la perspectiva de Adorno sobre la utopía y el comportamiento mimético de la obra de arte tanto con una noción hermenéutica de comprensibilidad de la experiencia estética como con una revalorización del carácter afirmativo de la praxis racional, ambas ausentes en Adorno. Pero al proceder de este modo, del planteo original de Adorno quedaría poco, ya que la dimensión utópica de la experiencia estética no tendría que ver con dos aspectos que resultaban fundamentales para el frankfurtiano: la estricta crítica de las formas de racionalidad social y la resistencia del arte a la comprensibilidad y a la transparencia de sentido. Sibien para Bertram el arte sería una autointerpretación de nosotros mismos y del mundo que produce transformaciones, una vez eliminado el negativismo social que guiaba al planteo de Adorno no se observa ningún puente que conecte el momento utópico, vislumbrado en la dimensión estética, con la esfera indicada por Adorno para llevar a cabo la transformación radical de la sociedad y crear las condiciones para la lograr la felicidad que el arte promete: la política. ${ }^{29}$

Las incipientes y prometedoras reflexiones de Rebentisch procuran aclarar esta zona de indeterminación entre la experiencia estética y la esfera política. Como hemos visto en los trabajos comentados, ella ha intentado mostrar cómo las operaciones de distanciamiento estético en relación con ciertas formas establecidas de identificación individual y social pueden ser consideradas como un momento constitutivo de la propia praxis social. Con este fin, Rebentisch vincula la especificidad de la obra de arte con la tendencia de la misma a exigir una atribución de sentido por parte del receptor y a poner en crisis de modo constante, siguiendo las reformulaciones de la estética negativa introducidas por Wellmer y Menke, toda posible cristalización de tales atribuciones. Las obras de arte harían posible así una experiencia que se caracterizaría por la tensión entre la percepción de un objeto de carácter material y la lectura simbólica del mismo. Y por este mismo motivo la experiencia estética se presentaría como portadora de un potencial político específico. Así, el comportamiento reflexivo de los receptores con respecto a sus representaciones subjetivas, el cual se pondría en marcha gracias a la experiencia estética, permitiría fracturar la fijación de las representaciones constituidas en el marco de la praxis política colectiva. 
No obstante, la redefinición del concepto de obra de arte, que sobre la base de la experiencia artística contemporánea realiza Rebentisch, pasa por alto o minimiza aquellos momentos en los cuales el arte, inclusive el más radical, deja de alentar el desarrollo de actitudes crítico-reflexivas para convertirse en parte de la propia "injusticia universal". Esa ambigüedad, que para Adorno impregnaba a las auténticas obras de arte, tiende a diluirse en el planteo de Rebentisch. Desde nuestra perspectiva, este hecho tiene como consecuencia una pérdida de la radicalidad adorniana en lo que respecta a la capacidad crítica sobre las demás esferas que le es adjudicada a la dimensión artística. Pues era justamente aquella participación en la "injusticia universal" la que, en el planteo adorniano, hacía posible entrelazar la negatividad estética con la crítica política radical sin que ninguna perdiese su propia especificidad.

En definitiva, los tres filósofos alemanes que tomamos en consideración no solo muestran que reflexionar sobre la relación entre la dimensión estética y otras esferas de la vida práctica sigue siendo una tarea delicada y necesaria. Ellos permiten advertir, además, que dicha reflexión aún tiene que comparecer frente a las pretensiones de verdad que habían sido elevadas por la estética negativa de Adorno. Aunque el precio a pagar por vindicar su actual fecundidad sea la aporía de distanciarse de las conexiones que daban impulso al pensamiento de Adorno.

En este sentido no es posible dejar de hacer referencia al distanciamiento de los autores que hemos considerado con respecto a la crítica totalizadora de la razón instrumental que había formulado Adorno y Horkheimer en "Dialéctica de la Ilustración". Una de las consecuencias más importante de este giro categorial remite a la posibilidad de ampliar el campo de la crítica política que es ejercida a partir de la dimensión artística. En el caso de Adorno, la forma de la crítica política del arte se reducía a la figura de la dialéctica de la apariencia estética: el arte era anticipo de la reconciliación y señalamiento, a la vez, de la no realización fáctica de la misma. Con el abandono de la absolutización adorniana de la razón identificante, se torna más específica la relación crítica del arte con la política de tal manera que este puede referirse de diversas maneras a las contradicciones sociales en el marco de las cuales está inserto. Sin duda, esta línea de crítica a Adorno es la que se encuentra en los autores considerados.

Sin embargo, la sustitución de los supuestos metafísicos de Adorno por la perspectiva pragmático-trascendental habermasiana también tiene como consecuencia una importante pérdida de radicalidad a la hora de pensar la relación crítica del arte con la política. De hecho, por más que Wellmer, Bertram o Rebentisch cuestionen el criterio normativo habermasiano de una 
comunicación libre de dominio, la racionalidad y el imperativo del consenso social continúan ocupando un lugar verdaderamente central. Esto es explícito en el caso de Bertram quien concibe la racionalidad de la obra de arte como "una racionalidad que muestra una posibilidad acerca de cómo podría ser desplazado el principio de la racionalidad". ${ }^{30}$ No obstante, también puede observarse en el pensamiento de Wellmer y de Rebentisch, aun cuando estos autores entiendan al arte como un espacio para la irracionalidad o para el desacuerdo. Podría decirse que para ellos se trata más de integrar por medio del arte experiencias ajenas al espíritu que de mostrar lo ajeno al sentido de aquellas capas de la realidad que se encuentran completamente atravesadas por el espíritu. En Adorno estos dos momentos coincidían en virtud de la dialéctica de la apariencia estética. Esta dialéctica colocaba en una relación de mutua dependencia a la capacidad crítica (y autocrítica) del arte y a su complicidad con las relaciones sociales existentes. Adorno no confiaba sin más en la posibilidad de una autoilustración de la institución artística o, mejor dicho, creía que esta autoilustración no podía sustraer al arte de su participación en la "injusticia universal". Por este motivo, contra la opinión de que la dialéctica adorniana de la apariencia estética se habría vuelto obsoleta para las discusiones contemporáneas, nos parece que su reformulación todavía continúa siendo una empresa prometedora para aquellas perspectivas que procuran repensar las relaciones actuales entre la experiencia estética y la dimensión política.

\section{Bibliografía}

ADORNO, Th. W. „Anton von Webern”. En: Gesammelte Schriften. Tomo XVII, Frankfurt a. M.: Suhrkamp, 1982. pp. 204-209.

. "Ästhetische Theorie". Frankfurt a. M.: Suhrkamp, 1973.

BERTRAM, G. „Das utopische Potencial der Kunst nach Theodor W. Adorno. Eine Reaktualisierung”. En: S. Vietta y S. Porombka (eds.). Ästhetik - Religion Säkularisierung. Die klassiche Moderne. Tomo II. München: Wilhelm Fink, 2009. pp. 247-263.

. "Kunst. Eine philosophische Einführung”. Stuttgart: Reclam, 2005.

BOHRER, K. H. "Plötzlichkeit. Zum Augenblick des ästhetischen Scheins". Frankfurt a. M.: Suhrkamp, 1981.

BORGDORFF, H. „Solidarität mit der Metaphysik nach ihrem Sturz. Einige Bemerkungen anlässlich Albrecht Wellmers Adorno-Lektüre“. En: O. Kolleritsch 
(ed.) Das Gebrochene Glücksversprechen. Zur Dialektik des Harmonischen in der Musik. Wien: Graz, 1998. pp. 80-102.

BUBNER, R. „Über einige Bedingungen gegenwärtiger Ästhetik”. En: Ästhetische Erfahrung. Frankfurt a. M.: Suhrkamp, 1982. pp. 7-51.

BÜRGER, P. "Crítica de la estética idealista". Madrid: Visor, 1996.

HONNETH, A. „Ein Artist der Dissonanz. Albrecht Wellmer und die Kritische Theorie". En: Dezernat Kultur und Wissenschaft der Stadt Frankfurt a. M. (eds.). Verleihung des Theodor-W.-Adorno-Preises 2006. Frankfurt a. M.: Imbescheidt $\mathrm{GmbH}, 2007$. pp. 6-15.

LEFORT, C., GAUCHET, M. "Sur la démocratie: la politique et l'institution du social". Textures, Nr. 2-3, 1971, pp. 79-130.

MENKE, Ch. "Estética y negatividad". Buenos Aires: Fondo de Cultura Económica, 2011.

. "La soberanía del arte". Madrid: Visor, 1997.

RANCIÈRE, J. “El desacuerdo". Buenos Aires: Nueva Visión, 1996.

REBENTISCH, J. “Ästhetik der Installation”. Frankfurt a. M.: Suhrkamp, 2003.

. "Die Kunst der Freiheit. Zur Dialektik demokratischer Existenz". Frankfurt a. M.: Suhrkamp, 2012.

SEEL, M. "Estética del aparecer". Buenos Aires: Katz, 2010.

. „Vor dem Schein kommt das erscheinen. Bemerkungen zu einer Ästhetik der Medien“. En: Ethisch-ästhetische Studien. Frankfurt a. M.: Suhrkamp, 1996. pp. 104-125.

WELLMER, A. „Adorno, die Moderne und das Erhabene“. En: Endspiele: Die unversöhhnliche Moderne. Frankfurt a. M.: Suhrkamp, 1993. pp. 165-190.

. „Das Versprechen des Glück und warum es gebrochen werden mu $\beta$ “. En: O. Kolleritsch (Ed.). Das gebrochene Glücksversprechen. Zur Dialektik des Harmonischen in der Musik. Wien: Universal-Edition, 1998. pp. 16-37.

. "La unidad no coactiva de lo múltiple. Sobre la posibilidad de una nueva

lectura de Adorno". En: A. Wellmer, V. Gómez. Teoría crítica y estética. Valencia: Universitat de València, 1994. pp. 17-45.

. "The Death of the Sirens and the Origin of the Work of Art". New German Critique, Nr. 81, pp. 5-19, 2000.

. „Wahrheit, Schein, Versöhnung”. En: Zur Dialektik von Moderne und

Postmoderne. Frankfurt a. M.: Suhrkamp, 1985. pp. 9-47.

WELSCH, W. "Grenzgänge der Ästhetik”. Stuttgart: Reclam, 1996. 